\title{
The combined effects of temperature and salinity on survival of postlarvae tiger prawn Penaeus monodon under laboratory conditions
}

\author{
Nilnaj Chaitanawisuti ${ }^{{ }^{*}}$, Wannanee Santhaweesuk ${ }^{1}$, Gullaya Wattayakorn $^{2}$ \\ ${ }^{1}$ Aquatic Resources Research Institute, Chulalongkorn University, Bangkok, Thailand; *Corresponding Author: cnilnaj@chula.ac.th \\ ${ }^{2}$ Department of Marine Science, Faculty of Science, Chulalongkorn University, Bangkok, Thailand
}

Received 23 April 2013; revised 23 May 2013; accepted 12 June 2013

Copyright (C) 2013 Nilnaj Chaitanawisuti et al. This is an open access article distributed under the Creative Commons Attribution License, which permits unrestricted use, distribution, and reproduction in any medium, provided the original work is properly cited.

\begin{abstract}
A $3 \times 4$ two-factor factorial experimental design with three replications per treatment was conducted to determine the effects three temperatures viz., room temperature $\left(29^{\circ} \mathrm{C} \pm 1^{\circ} \mathrm{C}\right)$ and elevated temperatures $\left(33^{\circ} \mathrm{C}\right.$ and $\left.35^{\circ} \mathrm{C} \pm 0.5^{\circ} \mathrm{C}\right)$ and four salinities $(25,30,33$ and $35 \mathrm{ppt})$ on survival of postlarvae tiger prawn Penaeus monodon under laboratory conditions. Results showed that temperature had a greater influence on survival of postlarvae $P$. monodon than salinity and low water temperature $\left(29^{\circ} \mathrm{C}\right)$ gave better larval survival than higher water temperatures $\left(33^{\circ} \mathrm{C}\right.$ and $\left.35^{\circ} \mathrm{C}\right)$. In addition, the PL1 had better tolerance to high temperatures than PL15. At the termination of the experiment, the best survival of PL1 was found at $29^{\circ} \mathrm{C}$ for all salinities tested with an average of $95.8 \%$, while the best survival of PL15 was also found at $29^{\circ} \mathrm{C}$ for all salinities tested with an average of $70.6 \%$. Based on survival at temperatures and salinities tested, the best salinity and temperature combination for the culture of $P$. monodon PL1 and PL15 were $29^{\circ} \mathrm{C}$ at $25,30,33$ and $35 \mathrm{ppt}$, and $29^{\circ} \mathrm{C}$ at 25 and $30 \mathrm{ppt}$, respectively.
\end{abstract}

Keywords: Penaeus monodon; Salinity;

Temperature; Postlarvae; Survival

\section{INTRODUCTION}

The tiger prawn Penaeus monodon is the most important penaeid species for mass hatchery production and land-based aquaculture system in Thialand and various countries in Asia. Shrimp farming is potentially affected by adverse physical, chemical, and biological conditions
$[1,2]$. Early life stages are the most sensitive phase in the complex life cycle of marine invertebrates and to maximise their survival larvae should be reared close to optimal conditions. Salinity and temperature are two of the most important abiotic factors affecting the growth and survival of aquatic organisms. Larval stages of most penaeid shrimp species occur in full strength seawater and at stable water temperatures. Hence, it is generally accepted that penaeid shrimps are not equipped with the capabilities of withstanding major environmental changes during their larval development. In addition, it is also well known that the response to these environmental parameters is species-specific and that salinity and temperature may also interact to influence growth and survival. It is generally agreed that temperature has a more pronounced effect on growth and survival of penaeids [3]. Many studies have reported on the effects of different environmental factors, in particular, salinity and temperature on development, survival and growth of various economical penaeid species [1,3-8]. Laboratory and field studies of responses of eggs and larvae of marine organisms to the combined effects of temperature and salinity would lead to a greater understanding of the significance of these factors on survival during early larval development. Thus, defining these optimal conditions for culture of euryhaline marine species may be the fundamental for developing rearing protocol for penaeid species. The purpose of the present study was to determine the survival of postlarvae Penaeus monodon at different combination of three temperatures $\left(29^{\circ} \mathrm{C}, 33^{\circ} \mathrm{C}\right.$ and $\left.35^{\circ} \mathrm{C}\right)$ and four salinities $(25,30,33$ and $35 \mathrm{ppt})$ during the early life stage development.

\section{MATERIALS AND METHODS}

The combined effect of salinity and temperature on survival of $P$. monodon postlarvae (PL) was determined 
in the laboratory using a $3 \times 4$ two-factor factorial experimental design was conducted with three temperatures viz., room temperature $\left(29^{\circ} \mathrm{C} \pm 1^{\circ} \mathrm{C}\right)$ and elevated temperature $\left(33^{\circ} \mathrm{C}\right.$ and $\left.35^{\circ} \mathrm{C} \pm 0.5^{\circ} \mathrm{C}\right)$ and four salinities $(25$, $30,33$ and $35 \mathrm{ppt})$. The experiment followed a completely randomized design, using the postlarvae stage (PL1 and PL15) from different spawners from private hatchery. Four batched of larvae were stocked into $10^{-1}$ cylindrical glass tanks at a density of $100 \mathrm{~L}^{-1}$ and they were acclimated to four salinity levels $(25,30,33$ and 35 ppt) by lowering the salinity at a rate of $5 \mathrm{ppt} \cdot \mathrm{h}^{-1}$. The required salinity was obtained either by diluting seawater with freshwater or by mixing filtered seawater with sea salt to keep variation within \pm 1 ppt. They were then acclimated to different temperatures at a rate of $5^{\circ} \mathrm{C} \cdot \mathrm{h}^{-1}$. A static-water system consisting of 36 aquaria ( $1 \mathrm{~L}$ glass beakers) with gently aeration was used and each aquarium held 20 individuals of postlarvae per treatment. Temperature was maintained within to $\pm 0.5^{\circ} \mathrm{C}$ using thermostatically controlled water baths. Each combination of temperature-salinity was conducted with three replications per treatment. Salinity and temperature were measured each morning using a portable refractometer and a mercury thermometer, respectively. All cultures were covered with aluminium foil to prevent evaporation. Gently aeration was provided in the container during the experiment. There was no feeding and water exchange during experiment for all treatments. Each experimental unit was initially examined the dead juveniles after $6 \mathrm{~h}$, and every $12 \mathrm{~h}$ thereafter. The experiments lasted $96 \mathrm{~h}$.
The number of larvae sank down to bottom of the aquaria was considered as dead as well as the juveniles did not react to the touch of a needle. The mean percentage of survival was calculated by combining the data from three replicates at the end of the experiment. Data from each treatment were subject to a two-way ANOVA. When overall differences were significant at less than 5\% level, Tukey test was used to compare the mean values between individual treatments. The square-root transformation of the sine-arc before analyzing the values given in percentages was used. Statistical analysis was performed using SPSS (statistic package for social science) 10.0 .

\section{RESULTS}

Table 1 showed percentage survival of $P$. monodon postlarvae through $96 \mathrm{~h}$ under different temperature and salinity combinations. Results showed that temperature had a greater influence on survival of $P$. monodon postlarvae than salinity and low water temperature $\left(29^{\circ} \mathrm{C}\right)$ gave better larval survival than higher water temperatures $\left(33^{\circ} \mathrm{C}\right.$ and $\left.35^{\circ} \mathrm{C}\right)$. In addition, the PL1 had better tolerance to high temperatures than PL15. Statistical analyses of the survival data by means of two-way ANOVA (Table 2) showed that temperature exerted a significantly higher influence on the survival at different stages of $P$. monodon from PL1-PL15 stages $(\mathrm{P}<0.05)$. The effect of temperature and temperature-salinity interaction was significant at 5\% level. At the termination of the experiment, the best survival of PL1 was found at

Table 1. Percentage survival of $P$. monodon postlarvae through $96 \mathrm{~h}$ under different temperature and salinity combinations.

\begin{tabular}{|c|c|c|c|}
\hline \multirow[t]{2}{*}{ Temperature $\left({ }^{\circ} \mathrm{C}\right)$} & \multirow[t]{2}{*}{ Salinity (ppt) } & \multicolumn{2}{|c|}{ Survival (\%) } \\
\hline & & PL1 & PL15 \\
\hline \multirow[t]{4}{*}{29} & 25 & $95.7 \pm 0.42^{\mathrm{a}}$ & $75.9 \pm 1.28^{\mathrm{a}}$ \\
\hline & 30 & $96.6 \pm 0.84^{\mathrm{a}}$ & $69.9 \pm 1.27^{\mathrm{b}}$ \\
\hline & 33 & $94.1 \pm 0.49^{\mathrm{a}}$ & $65.2 \pm 0.99^{\mathrm{c}}$ \\
\hline & 35 & $97.1 \pm 0.57^{\mathrm{a}}$ & $71.4 \pm 0.85^{\mathrm{a}}$ \\
\hline \multirow[t]{4}{*}{33} & 25 & $87.9 \pm 1.06^{\mathrm{b}}$ & $69.0 \pm 1.34^{\mathrm{b}}$ \\
\hline & 30 & $86.2 \pm 0.98^{\mathrm{b}}$ & $65.1 \pm 0.78^{\mathrm{c}}$ \\
\hline & 33 & $87.3 \pm 0.71^{b}$ & $66.5 \pm 0.78^{\mathrm{c}}$ \\
\hline & 35 & $86.9 \pm 1.49^{\mathrm{b}}$ & $68.2 \pm 0.42^{\mathrm{b}}$ \\
\hline \multirow[t]{4}{*}{35} & 25 & $64.6 \pm 0.78^{\mathrm{c}}$ & $37.1 \pm 1.56^{\mathrm{e}}$ \\
\hline & 30 & $69.2 \pm 0.98^{\mathrm{c}}$ & $43.7 \pm 1.49^{\mathrm{d}}$ \\
\hline & 33 & $68.9 \pm 1.34^{\mathrm{c}}$ & $47.1 \pm 1.27^{\mathrm{d}}$ \\
\hline & 35 & $76.3 \pm 0.70^{\mathrm{c}}$ & $44.6 \pm 0.85^{\mathrm{d}}$ \\
\hline
\end{tabular}

Mean in the same column with different superscript letters are significantly different $(\mathrm{P}<0.05)$. 
Table 2. Results of two-way ANOVA for survival of $P$. monodon postlarvae through $96 \mathrm{~h}$ under different temperature and salinity combinations at $95 \%$ confidence interval.

\begin{tabular}{|c|c|c|c|c|c|}
\hline Parameters & Sum of square & d $f$ & Mean square & F-value & P-value \\
\hline \multicolumn{6}{|c|}{ Postlarvae stage (PL1) } \\
\hline Corrected model & $4246.765^{\mathrm{a}}$ & 11 & 386.070 & 293.589 & 0.000 \\
\hline Intercept & 89377.215 & 1 & 89377.215 & 67967.464 & 0.000 \\
\hline Temperature & 3907.922 & 2 & 1953.961 & 1485.902 & 0.000 \\
\hline Salinity & 41.515 & 3 & 13.838 & 10.523 & 0.001 \\
\hline Temperature $\times$ salinity & 297.328 & 6 & 49.555 & 37.684 & 0.000 \\
\hline Error & 15.780 & 12 & 1.315 & & \\
\hline Total & 93639.760 & 24 & & & \\
\hline Corrected Total & 4262.545 & 23 & & & \\
\hline \multicolumn{6}{|c|}{ Postlarvae stage (PL15) } \\
\hline Corrected model & $2992.991^{\mathrm{a}}$ & 11 & 272.090 & 289.329 & 0.000 \\
\hline Intercept & 170302.954 & 1 & 170302.954 & 181093.083 & 0.000 \\
\hline Temperature & 2843.192 & 2 & 1421.596 & 1511.666 & 0.000 \\
\hline Salinity & 55.355 & 3 & 18.452 & 19.621 & 0.000 \\
\hline Temperature $\times$ salinity & 94.444 & 6 & 15.741 & 16.738 & 0.000 \\
\hline Error & 11.285 & 12 & 0.940 & & \\
\hline Total & 173307.230 & 24 & & & \\
\hline Corrected total & 3004.276 & 23 & & & \\
\hline
\end{tabular}

R Squared $=0.996$ (Adjusted R Squared $=0.993)$.

$29^{\circ} \mathrm{C}$ for all salinities with an average of $95.8 \%(94.1 \%$ $97.1 \%$ ), while the lowest survival of PL1 was found at $35^{\circ} \mathrm{C}$ for all salinities with an average of $69.8 \%(64.6 \%$ $76.3 \%$ ). In contrast, the best survival of PL15 was found at $29^{\circ} \mathrm{C}$ for all salinities with an average of $70.6 \%$ $(65.2 \%-75.9 \%)$, while the lowest survival was found at $35^{\circ} \mathrm{C}$ for all salinities with an average of $43.1 \%$ (37.1\% $47.1 \%)$.

\section{DISCUSSION}

The present study showed that temperature had a greater influence to postlarvae tiger prawn $P$. monodon than salinity and low water temperature $\left(29^{\circ} \mathrm{C}\right)$ gave better larval survival than higher water temperatures $\left(33^{\circ} \mathrm{C}\right.$ and $35^{\circ} \mathrm{C}$ ). In addition, the PL1 had better tolerance to high temperatures than PL15. The best survival of PL1 was found at $29^{\circ} \mathrm{C}$ for all salinities tested with an average of $95.8 \%$ as compared to $70.6 \%$ for those of PL15. The elevated temperature might be suitable for growth of aquatic animals, but it had an inverse effect on survival [3]. Consistent with our study, temperature, salinity, shrimp size and the interaction of these parameters significantly influence the specific oxygen consumption of shrimp Litopenaeus vannamei. At $25^{\circ} \mathrm{C}$ and $30^{\circ} \mathrm{C}$ oxygen consumption was more stable at salinities $13 \%$ and $25 \%$ for all groups. At $20^{\circ} \mathrm{C}$ and salinity below $25 \%$ oxygen consumption was higher, possibly due to the reduced hyperosmoregulatory ability in lower temperatures [9]. Maximum survival of the larval stages of $P$. merguiensis during the protozoeal stages also had been reported at 35 ppt followed by $48 \%$ at $33^{\circ} \mathrm{C}$ and $45 \%$ at $29^{\circ} \mathrm{C}$ and salinity exerted a greater influence than temperature on the survival and development of larvae. Based on the results, the best temperature-salinity combination for larval survival and metamorphosis is $33^{\circ} \mathrm{C}$ and 35 ppt. A salinity range of $30-35 \mathrm{ppt}$ is ideal for larval development [2]. A reduction in temperature level was also found resulting in a decreased osmoregulatory capacity of farmed shrimp $P$. stylirostris at low salinity and at high salinity, respectively, below and above the isoosmotic point (26.2 ppt). Furthermore, the sensitiveness of osmoregulation to temperature changes was dependent on the developmental stage of the shrimp. Subadults were more sensitive than juvenile animals [10]. Similar effects temperature and salinity on various marine and freshwater penaeid shrimp species are found. Juveniles of P. vannamei have 
their best survival between temperatures of $20^{\circ} \mathrm{C}$ and $30^{\circ} \mathrm{C}$ and salinities above $20 \%$. Best growth was obtained between temperatures of $25^{\circ} \mathrm{C}$ and $35^{\circ} \mathrm{C}$, with little difference being noted among salinities. Survival and growth coincide best at around $28^{\circ} \mathrm{C}$ to $30^{\circ} \mathrm{C}$ and $33 \%$ to $40 \%$. In addition, many studies also indicated the effect of high temperature on development and growth of penaeid species but not for survival [8]. Development rate from the naupliar stage to the protozoal stage of Metapenaeus monoceros was best at a salinity level of 35 $\mathrm{g} \cdot \mathrm{L}^{-1}$ combined with temperatures of $28^{\circ} \mathrm{C}$ and $32^{\circ} \mathrm{C}$ and larval activity was found to be best at $28^{\circ} \mathrm{C}$ and $32^{\circ} \mathrm{C}$ at $35 \mathrm{~g} \cdot \mathrm{L}^{-1}$ and $40 \mathrm{~g} \cdot \mathrm{L}^{-1}$, as compared to that at $24^{\circ} \mathrm{C}$ in all salinity levels [4]. Growth of the prawn Macrobrachium rosenbergii was also increased as temperature increased from $26^{\circ} \mathrm{C}$ to $30^{\circ} \mathrm{C}$ then the growth declined at the highest temperature $\left(34^{\circ} \mathrm{C}\right)$. Also as salinity increased from 0 to $16 \mathrm{ppt}$, growth of females decreased at all temperatures tested. It was clearly found that optimum level of both temperature and salinity for growth, reproduction and hatching success of $M$. rosenbergii was $30^{\circ} \mathrm{C}$ temperature and $6 \mathrm{ppt}$ salinity [5]. In addition, larvae Pandalus jordani were shown to have a wide tolerance to salinity, especially in the early stages, but a relatively narrow tolerance to temperature. The optimal temperatures for survival, $8^{\circ} \mathrm{C}$ to $11^{\circ} \mathrm{C}$, were also optimal for growth as reflected by maximal growth increments and body size. It is therefore felt that fluctuations in temperature as seen within and between successive larval seasons would have profound effects on larval survival, growth rates and size at metamorphosis to the benthic juvenile phase [1]. Temperature also exerted a greater influence than the salinity on the growth and survival of $P$. semisulcatus during the larval development. The range of temperature in which the larvae showed high survival and growth is relatively narrow as compared to that of salinity. At all salinity levels, survival to PL1 $(69 \%-77 \%)$ was higher at $26^{\circ} \mathrm{C}$ as compared to $30^{\circ} \mathrm{C}(44 \%-73 \%)$ and $34^{\circ} \mathrm{C}$ $(14 \%-21 \%)$. However, daily growth rate at $30^{\circ} \mathrm{C}$ and $34^{\circ} \mathrm{C}$ was about $60 \%$ higher than at $26^{\circ} \mathrm{C}$. Larval development was also $3-4$ days faster at $30^{\circ} \mathrm{C}$ and $34^{\circ} \mathrm{C}$. Based on the survival and growth results, the best salinity and temperature combination for the culture of $P$. semisulcatus were $30 \mathrm{ppt}$ and $30^{\circ} \mathrm{C}$ [3]. Jackson and Burford (2003) found that salinity did not have a significant effect on growth or survival of $P$. semisulcatus larvae above $28 \%$. At $28 \%$, both growth rate and survival decreased, and there was significantly lower survival at the higher temperatures $\left(32^{\circ} \mathrm{C}\right.$ and $\left.29^{\circ} \mathrm{C}\right)$.

\section{ACKNOWLEDGEMENTS}

This research was partially supported by the Higher Education Research Promotion and National Research University Project of Thailand, Office of the Higher Education Commission (CC1030A) and the Inte- grated Innovation Academic Center: IIAC Chulalongkorn University Centenary Academic Development Project (CU56-CC06). The authors thank Sichang Marine Science Research and Training Station, Aquatic Resources Research Institute, Chulalongkorn University, in particular Mr. Soontorn Thepmoon for his help and suggestion during the experiments.

\section{REFERENCES}

[1] Aktas, M.S. and Nuran, A. (2012) The combined effects of salinity and temperature on the egg hatching rate, incubation time, and survival until protozoal stages of Metapenaeus monoceros (Fabricius) (Decapoda: Penaeidae). Turkish Journal of Zoology, 36, 249.

[2] Babu, S., Shailender, M., Sarmai, K.P. and Kishor, B. (2012) Effects of temperature and salinity on growth, hatching rate and survival of the giant freshwater prawn, Macrobrachium rosenbergii under captive conditions. International Journal of Bioassays, 1, 150-155.

[3] Bett, C. and Vinatea, L. (2009) Combined effect of body weight, temperature and salinity on shrimp Litopenaeus vannamei oxygen consumption rate. Brazil Journal of Oceanography, $\mathbf{5 7}$.

[4] Hernandez, M.S., Calos, A., Palacios, A.M, Ruth, C., Perez, V., Rosas, C. and Ross, L.G. (2005) The combined effects of salinity and temperature on the oxygen consumption of juvenile shrimps Litopenaeus stylirostris (Stimpson, 1874). Aquaculture, 244, 341-348.

doi:10.1016/j.aquaculture.2004.11.023

[5] Jackson, C.J. and Burford, M. (2003) The effects of temperature and salinity on growth and survival of larval shrimp Penaeus semisulcatus (Decapoda: Penaeoidae). Journal of Crustacean Biology, 23, 819-826. doi:10.1651/C-2379

[6] Kumlu, M., Eroldogan, O.T. and Aktas, M. (2000) Effects of temperature and survival on larval growth, survival and development of Penaeus semisulcatus. Aquaculture, 188, 167-173. doi:10.1016/S0044-8486(00)00330-6

[7] Lemairea, P., Bernarda, E., Martinez-Pazb, J.A. and Chima, L. (2002) Combined effect of temperature and salinity on osmoregulation of juvenile and subadult Penaeus stylirostris. Aquaculture, 209, 307-317. doi:10.1016/S0044-8486(01)00756-6

[8] Palafox, J.P., Palacise, C.A.M. and Ross, L.G. (1997) The effects of salinity and temperature on the growth and survival rates of juvenile white shrimp, Penaeus vannamei, Boone, 1931. Aquaculture, 157, 107-115. doi:10.1016/S0044-8486(97)00148-8

[9] Rothlisberg, P.C. (1979) Combined effects of temperature and salinity on the survival and growth of the larvae of Pandalus jordani (Decapoda: Pandalidae). Marine Biology, 54, 125-134. doi:10.1007/BF00386591

[10] Zacharia, S. and Kakati, V.S. (2004) Optimal salinity and temperature for early developmental stages of Penaeus merguiensis De man. Aquaculture, 232, 373-382. doi:10.1016/S0044-8486(03)00538-6 